\title{
Research on the innovation Closed-loop Internet financial service model of traditional industry
}

\author{
Maoguang Wang*, Leilei Ge, Jiangping Zhao \\ School of Information \\ Central University of Finance and Economics \\ Beijing, China \\ mgwangtiger@163.com, geleilei1994@sina.com
}

\begin{abstract}
Recently, the focuses on Chinese development are the optimization and upgrading of Chinese traditional industries. It is also a main link during the realization of various corporations' sustainable development. However, many problems like capital, labor and thought rise during the processing of upgrading. What's more, it is a trend today that we can develop the internet and traditional industries by combining them together. This paper analyzes the question of traditional industries, discusses the combination of traditional industries, the Internet finance and online-to-offline platform which is closedloop. It also studies the case of Wanda, analyzes the concrete form and puts forward the improvement proposals in big data and electronic contract.
\end{abstract}

Keywords - traditional industries; Internet Finance; online-tooffline platform; closed-loop

\section{INTRODUCTION}

It has already been a trend for Chinese industries to realize the transformation and upgrading in recent years. It is difficult to achieve sustainable growth in all kinds of industries if they are not able to change their development patterns, especially in traditional industries which are facing problems like production capacity surplus, increasing cost, imbalance between supply and demand and so on. The recently issued national file which called the 13th Five-Year Plan has pointed clearly that every industry needs to execute the "Internet Plus" action plan, develop IOT(internet of things) technology and applications, develop the sharing economy and promote the integration of the Internet and social economy. What's more, they are supposed to encourage the innovation of industry organization, business model, supply chain and logistics chain etc. It is said that optimizing and upgrading the traditional industries by the internet including the internet finance, has been a key of developing the Chinese economy.

Generally speaking, the traditional industry means laborintensive industry. Now they have realized the necessity of transformation and upgrading during the trend of reform and transformation in China. Meanwhile, the transformation and upgrading of traditional industries need a lot of money, talents and technologies. Especially, to adapt to these changes enterprises should improve the business model and cultivate the internet thinking. In the past enterprises rely on the closedloop and long-tail effect of barriers or monopoly business model which make use of the asymmetric information to increases the intermediate profits.
Therefore, the optimization and upgrading of the traditional industries needs a comprehensive reform. Its combination with internet financial is making full use of the internet advantages. They are supposed to use the appropriate model and combine them properly. Therefore, it is necessary to research on an applicable "financial Internet plus" model.

\section{RELATED WORKS}

The year of 2015 is a crucial moment for China's industries to adapt to new economy changes. Gu [1] focused on the traditional retailers' transformation in the Internet era. He analyzes the traditional problems encountered in the development of retail enterprises through documentary analysis and case study method. Shi [2] studied the famous company of Suning and summed up the e-commerce experience by literature surveys and case studies. In addition, the combination of traditional industries and the $\mathrm{O} 2 \mathrm{O}$ platform has become a research hot topic. Liu [3] studied the O2O commerce models and investigated three companies' O2O model applications. Shi [4] concluded that $\mathrm{O} 2 \mathrm{O}$ can help company achieve the goal of business innovation. What's more, the new model can enable enterprises to meet the growing needs of customers and eventually improve the sales.

As to closed-loop O2O platform structure, Zhao [5] summarizes the characteristics of closed-loop O2O: big data, circulation and resource integration. Zhao and Liao [6] study the $\mathrm{O} 2 \mathrm{O}$ model and pointed that common $\mathrm{O} 2 \mathrm{O}$ model's biggest drawback is that it is difficult to complete closed-loop and it wastes a lot of human resources. By data analysis and market research, they concluded that companies should take effective measures including the integration from online to offline, the introduction of adequate online flow and the establishment a good consumer feedback system.

At present, all major companies are engaged in building industry ecosystems. Three Chinese internet giants called BAT are accelerating their paces on O2O. Baidu owns some platforms including Baidu Nuomi and Baidu Map, and by using them Baidu connects theaters, restaurants, hotels, services, transportation, convenience stores, tourist spots and other areas to build the LBS(Location Based Service) ecosystem. Alibaba has bought Gaode Map and integrates its navigation function with Taodiandian and Taobao platform to create an $\mathrm{O} 2 \mathrm{O}$ chain like "Alipay+ Meituan+ Gaode Map+ Taodiandian+ Weibo+ Juhausuan”. Meanwhile, Tencent 
combines Wechat, SOSO Map, Dianping, Gaopeng, Didi and other live services platforms. As we can see, $\mathrm{O} 2 \mathrm{O}$ and closedloop model are the focuses of the industry, which are becoming more and more concerned.

\section{The InNovative Closed-Loop Model}

Traditional industries can take advantage of the internet to attract customers, master payment link in the transaction process. The key of the sustainable development is to construct a closed-loop of the entire industry chain, which finally form a capital and information ecosystem.

First of all, O2O closed-loop refers to the resource flow can form a ring between online and offline, including consumers, portals, scenarios, payments and service experiences, which is an important feature of $\mathrm{O} 2 \mathrm{O}$ platform and differentiate it from other information platforms. Secondly, the complex closedloop integrates more functions to the platform. For instance, the combination of $\mathrm{O} 2 \mathrm{O}$ trading closed-loop and the internet finance can make up for the financial credit problems, strengthen risk control and so on.

As shown in Fig.1, it is the industry's ecosystem of the innovation mode of the traditional industries involved with the Internet Financial closed-loop service. Now suppose that graph $\mathrm{G}=\langle\mathrm{V}, \mathrm{E}>$ which is a directed graph. And $\mathrm{V}=\{\mathrm{V} 1, \mathrm{~V} 2, \ldots, \mathrm{Vn}\}$ represents $\mathrm{O} 2 \mathrm{O}$ platforms, consumers, businessmen, lifeservice institutions, financial service institutions, the third party payment institutions and logistics etc. E describes their relationship. Directed edges between two vertices represent the link between vertices. We now suppose that the cost of edge $E_{i j}$ is $c_{i j}$, the revenue is $e_{i j}$ and the cost-effectiveness rate of the network is $\frac{\sum \mathrm{c}_{\mathrm{ij}}}{\sum \mathrm{e}_{\mathrm{ij}}}$ ( $\mathrm{i}$ and $\mathrm{j}$ are points on the selected paths). After considering all the paths, we would select one which satisfies $\theta_{\max }=\max \frac{\sum \mathrm{c}_{\mathrm{ij}}}{\sum \mathrm{e}_{\mathrm{ij}}}$ ( $\mathrm{i}$ and $\mathrm{j}$ are nodes on the selected paths). And the paths being selected is the optimal cost-efficiency path.

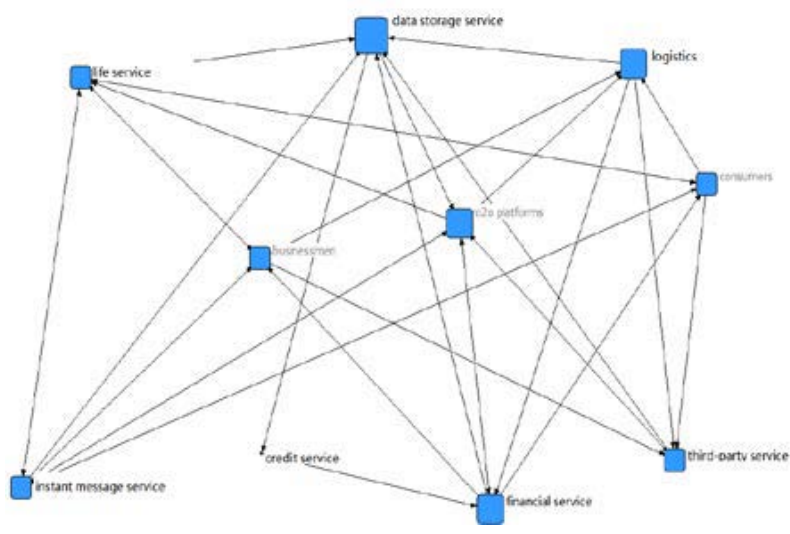

FIGURE 1. THE GRAPH STRUCTURE FOR CLOSED-LOOP BUILT ON O2O

O2o platform mainly controls two links between sellers and consumers including information flow, capital flow, and collects consumer data, provides customer service evaluation and reputation services for offline businesses illustrated in Fig.2.

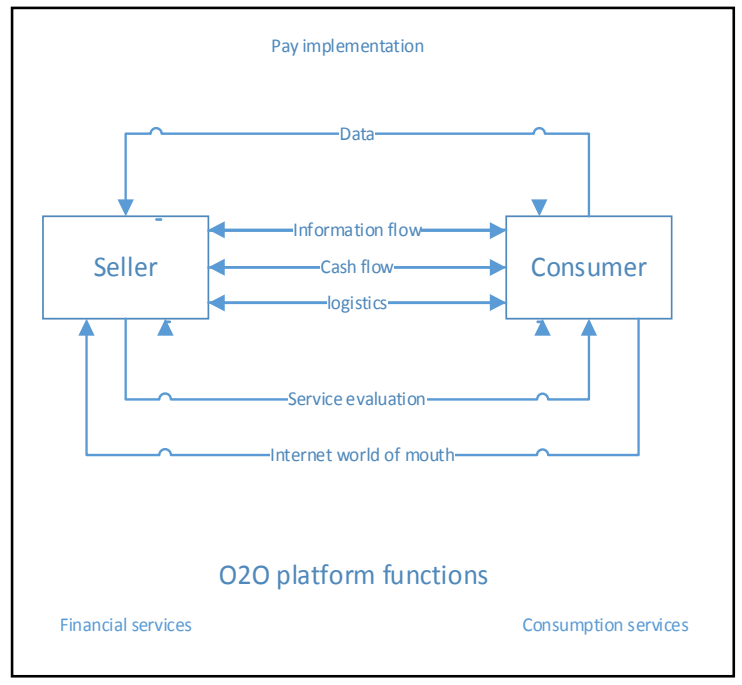

FIGURE 2. CLOSED-LOOP FOR SELLER AND CONSUMER

Below is the explanation for the information and capital links among businessmen, $\mathrm{O} 2 \mathrm{O}$ platform and customers so on, which is summarized in table I.

TABLE I. THE CLOSED-LOOP INFORMATION INTERACTIONS

\begin{tabular}{|c|c|c|}
\hline objects & The cash flow & The information flow \\
\hline $\begin{array}{l}\text { Consumers } \\
\text { and } \\
\text { Businessmen }\end{array}$ & $\begin{array}{l}\text { (1)consumers } \rightarrow \text { the third } \\
\text { party of payment } \\
\text { institutions } \rightarrow \text { businessmen } \\
\text { (2)consumers } \rightarrow \text { logistics } \\
\text { (3)businessmen } \rightarrow \text { logistics }\end{array}$ & $\begin{array}{l}\text { consumers } \rightarrow \text { businessmen } \rightarrow \text { i } \\
\text { nstant message services } \\
\text { consumers }\end{array}$ \\
\hline $\begin{array}{l}\text { Consumers } \\
\text { and } \\
\mathrm{O} 2 \mathrm{O} \\
\text { platform }\end{array}$ & $\begin{array}{l}(1) \mathrm{O} 2 \mathrm{O} \\
\text { platform } \rightarrow \text { financial service } \\
\text { institutions } \rightarrow \text { consumers } \rightarrow \\
\text { the third party of payment } \\
\text { institutions } \rightarrow \text { O2O } \\
\text { platforms } \\
(2) \mathrm{O} 2 \mathrm{O} \text { platforms } \\
\text { logistics }\end{array}$ & $\begin{array}{l}\text { (1)O2O platforms } \rightarrow \text { di rect- } \\
\text { instant message } \\
\text { services } \rightarrow \text { consumers } \rightarrow \mathrm{O} 2 \mathrm{O} \\
\text { platforms } \\
\text { (2)O2O platforms } \mathrm{life} \\
\text { service institutions, finance- } \\
\text { service institutions, } \\
\text { logistics } \rightarrow \mathrm{O} 2 \mathrm{O} \text { platforms }\end{array}$ \\
\hline $\begin{array}{l}\text { Businessmen } \\
\text { and } \\
\mathrm{O} 2 \mathrm{O} \\
\text { platforms }\end{array}$ & $\begin{array}{l}(1) \mathrm{O} 2 \mathrm{O} \\
\text { platforms } \rightarrow \text { financial } \\
\text { service institutions, life } \\
\text { service institutions } \\
\rightarrow \text { businessmen } \rightarrow \text { the third } \\
\text { party of payment } \\
\text { institutions } \rightarrow \text { O2O } \\
\text { platforms } \\
\text { (2)businessmen } \rightarrow \text { logistics } \\
\text { (3)O2O platforms } \\
\text { logistics }\end{array}$ & $\begin{array}{l}\text { (1)o2o platforms } \rightarrow \text { instant } \\
\text { message services } \rightarrow \\
\text { consumers } \rightarrow \text { o2o platforms } \\
\text { (2)o2o platforms financial } \\
\text { service institutions, logistics, } \\
\text { the third party of payment } \\
\text { institution, life service } \\
\text { institutions } \rightarrow \mathrm{O} 2 \mathrm{O} \text { platforms }\end{array}$ \\
\hline
\end{tabular}

The important closed-loop is represented by the cash flow, information flow and logistics etc. In the view of information path, the closed-loop can be divided into two kinds. One is the personal closed-loop by instant message service. The other is the public closed-loop by the financial services, life services and so on. Furthermore, O2O platform provide the universal portal service, which combines the customer behaviors and other services together. Now companies are improving their portal platform to integrate the map services, taxi services, food services and so on. The technologies including cloud computing, big data, Internet of Things facilitate the establishment of a complex industry ecosystem. To build a closed-loop, it is important to optimize the profit. Usually, the costs are supposed to be as low as possible in accordance with 
the profits.

Closed-loop O2O structure has many advantages. First, it provides new business models for the companies. Based on the $\mathrm{O} 2 \mathrm{O}$ platform, the traditional business work-flow will be improved greatly because the information is becoming more apparent and the trade is more convenient. Second, closed-loop $\mathrm{O} 2 \mathrm{O}$ services integrates rich data including customer behaviors, trading data and their personal hobbies etc. Therefore, companies are capable of making full use of big data technologies to mine personal preference and provide new products to attract customer to consume online and offline. Third, to meet the demands of building the credit system in China, now O2O platform provide the opportunities to build the personal and enterprise credit system.

\section{CASE ANALYSIS}

Wanda Commercial Real Estate Co., Ltd was established in September 2002 belongs to Dalian Wanda Group. It is a commercial real estate investments and operations company. The company's main business is commercial real estate investment and management, whose core products is "Wanda Plaza" named after Wanda urban complex.

Wanda urban complex means building a large-scale Wanda Plaza. It can also support the construction of a number of offices, shops, houses near its plaza. It used to put matching property for sale, and use the cash flow derived from sales to invest and hold other Wanda Plazas. Because of China lacking the long-term financial products which mainly support real estate investment, Wanda usually can only rent by sale. After Wanda Plaza completing their operations, all rental income will be owned by Wanda, which is a model of asset-heavy development. From 2013, Wanda has taken a lot of actions to complete transformation and developed an asset-light model. In this mode, investors invest Wanda Plazas' construction, and then Wanda will be responsible for selecting site to construct, designing, constructing, recruiting and managing, with the brand Wanda Plaza and using the world's original "intelligent cloud" systems. The rental income will be distributed by a certain percentage between Wanda and merchants. In addition, Wanda, Tencent and Baidu have set up an e-commerce company, after purchasing Fast Money, and developed an internet financial product called "1st Wenzhuan". It completes internal access to funds. Wanda Group is ready to take the integration of other modules such as culture and tourism into account and form a complete ecosystem. We can see Wanda's determination of transformation clearly everywhere in their 2015 development plan where they are supposed to strive to upgrade their transition from commercial real estate mode to the internet services model. Wanda has put up the goal of achieving the "2211" project, which is that by 2020, Wanda will have made its assets reach to $\$ 200$ billion; its market value to $\$ 200$ billion; its revenue reach to $\$ 100$ billion; its profit reach to 10 billion and the goal of becoming the world's leading multinational enterprise. Wanda's industrial closedloop mode

The closed loop model Wanda has launched is shown in Fig.3.

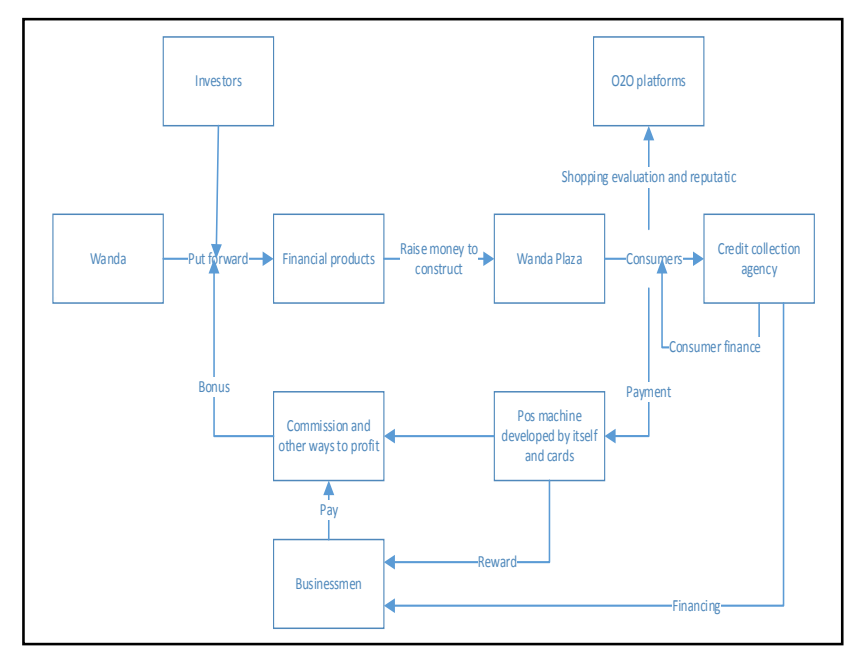

FIGURE 3. WANDA'S INDUSTRIAL CLOSED-LOOP MODEL

As shown in Fig.3, Wanda commercial closed-loop mainly complete capital flow and information flow loop. The capital closed-loop goes like this: Wanda launches the internet financial products to raise money to build Wanda Plaza, attracts customers to go shopping in the Wanda Plaza through the $\mathrm{O} 2 \mathrm{O}$ platform. They encourage customers to use POS machines and business cards to consume. The businessmen in Wanda Plaza will pay the rent. Then Wanda uses rent as bonuses for investors. And the closed-loop information flow is represented by $\mathrm{O} 2 \mathrm{O}$ platform's advertisements and business process to attract customers. The customer is able to evaluate the service by online submission. What's more, by the accumulation of credit records of consumers, Wanda is capable of making full use of the big data to establish the credit report platform and develop new products. Wanda benefit from the closed-loop model.

\section{1) financial product and profit}

Wanda used to increase the sales to support the plaza rent. Now Wanda actively develop new products. Its first crowdfunding financial product called "the 1st Wenzhuan" was sold out at one moment from the June 12th to June 15th, creating, which was a new record in the field of crowdfunding. And its money amount to five billion will be used to construct 5 nationwide Wanda Plazas. Wanda Plaza use rentals to pay for investors as bonuses and investment return. This kind of financial products has the advantages of low risk and high profit compared with stocks and bonds. That's why although "the 1st Wenzhuan" has a long return period, it still attracted a large number of investors.

2) the POS machine and their own card

A key step in the formation of a closed-loop model is to have a means of payment developed by itself. The consumer data need to be reflected through the payment. However, people are accustomed to using Alipay and Wechat-payment. If the platform does not develop their own means of payment, Wanda will for sure to be bound by others. So, Wanda has independently developed the POS payment machine itself, and gives subsidies and incentives to online businesses. 


\section{3) $O 2 O$ platform and credit report}

Wanda's O2O platform is still an important link. Unlike the Alibaba, Jindong and a number of e-commerce platforms, Wanda mainly uses the $\mathrm{O} 2 \mathrm{O}$ platform for customer consumption evaluation, services such as ordering meals, parking and so on. Wanda is attracting consumer and collect consumer data to build the credit report. Now data is valuable asset. By analyzing the information of consumers, merchants, and payments etc., Wanda is able to develop customized products and increase its competitiveness.

\section{CONCLUSIONS}

Many companies are developing their O2O closed-loop to integrate new products and business models. In China the socalled industry ecosystem mainly depend on the IT technologies. But there are some problems to solve such as security, risk control etc. We will further to study the innovative bushiness models and apply them to the industry.

\section{ACKNOWLEDGMENT}

This work is supported partially by NSFC under the Agreement No. 61073020 and the Project of CUFE under the Agreement No. 020674115002,020676114004, 020676115005.

\section{REFERENCES}

[1] Gu Wei. The Analysis of Traditional Retailer Transformation in Internet Time-Take Suning Appliance as Example[D].Shanghai : Shanghai International Studies University, 2014.

[2] Shi Lei. Study on The Strategic Transformation of developing ecommerce in Traditional Retail Enterprises-the Case Analysis Based on Suning[D].Tianjin: Tianjin University, 2013.

[3] Liu Xiaohong. The Research on O2O Operation Model of Electronic Commerce in China- a Case of H Company [D].Jilin: Jilin University 2015

[4] Shi Chunjia. A Master Thesis Submitted to University of Electronic Science and Technology of China[D].Chengdu : University of Electronic Science and Technology, 2013.

[5] Zhao Sujuan. The Study on The Mode of O2O Closed-loop[J]. Management \& Technology of SME, 2014 (21).

[6] Zhao Wenfeng\&Liao Zelong.The Analysis on The Mode of O2O Business[J]. Science and Technology, 2015 (15).

[7] Peng Hui\&Wu Li.O2O E-commerce: Power, Patterns and Prospects [N] . Journal of South China University of Technology, 2014-12 (06).

[8] Chen Yang. O2O: the marketing closed-loop online to offline[N]. New Marketing, 2013(2).

[9] City Express. Traditional Business is Facing the disappearance Do Yintai Department Store will Become Ali Department Store? [N]. City Express,2015-05-19. 